reactions on various time scales".

Biology has much to offer for our understanding of the many problems which beset mankind and Professor Young takes pains to show that this is so. Yet Professor Young feels, in all humility, that as an introduction to the study of man (or perhaps more appropriately the "condition" of man) his book does not go far enough. He feels it is "unbalanced", even "superficial", because "it contains little about aesthetics, emotions, or spiritual life; nothing of humour, acting, music, or literature; nothing of architecture or invention, economics, sociology, or law; little of human joys and sorrows". But how much further can biological insight take us? It is not that Young wishes to promote a Wellsian, worldbrain self-educator, but he feels that biology somehow should have more to offer for our understanding of these aspects of the "essence of life". $\mathrm{He}$ himself suggests tentatively that many social or cultural activities and institutions should be looked upon as manifestations of the biological urge to survival and to homoeostasis.

This then is essentially a book of ideas and principles. Though it presupposes a reasonable general knowledge of basic science it is not a technical work since it is not concerned with the methods by which the functional or structural properties of the living body are observed or measured or populations investigated. Even so, it is very much the product of an experimentalist since Young is always critically concerned not to overstate the extent of our real knowledge of form and function. $\mathrm{He}$ constantly draws attention to problems crying out for investigation.

In its combination of biological erudition, concern for profound issues, scientific and social, sensitivity to the problems of mankind and not least to values and aspirations, this is a work of rare distinction. J. S. WEINER

\section{Go to the Ant}

Insect Societies. By Edward O. Wilson. Pp. $\mathrm{x}+584$. (Belknap: Cambridge, Massachusetts. Published for Harvard University Press, August 1972.) £9.50.

IN the literature of the late nineteenth century we can trace the emergence of a popular stereotype of the entomologist - as an elderly amateur with glasses and a butterfly net, apt to talk to himself and more or less mad (not always harmlessly). This figure has almost disappeared today, though traces of him linger, for example, in Nabokov. The professional entomologists of our century can hardly be said to have earned a recognizable literary image, though among the generality of their fellow scientists they probably have the repute of being more than usually narrowminded and petty. No one would expect an entomologist to win a Nobel prize, appear as a major scientist in the mass media, or reach the top positions in the Royal Society.

There are, however, entomologists today who can hardly be dismissed as petty or narrow-minded, and a prominent American example is provided by E. O. Wilson. His specialist work on ants has broadened to include almost every aspect of their life and evolution, and now culminates in a large work, the worthy successor of W. M. Wheeler's classic, dealing with the whole subject of social life in insects from the broadest evolutionary-biological point of view. The book is well illustrated, and written in a clear direct style, with such specialist technical terms as Wilson feels obliged to use explained in a glossary;evidently he is anxious to reach a wider audience than that provided by professional entomologists - as indeed the book deserves to do

The author begins by summarizing current knowledge of each of the principal groups of social insects in turn, in 113 pages, pride of space naturally going to the ants, with forty-eight pages to only seventeen on termites. These accounts, compared with Wheeler's, include much significant information which was not known in 1928, and a good deal that has not yet found its way into the general literature. The extensive bibliography includes numerous works from 1969 and a few from 1970. The least satisfactory part of these chapters is probably his treatment of classification-presented in summary tables down to the genus level but with no characterizations of any of the taxa and no serious questioning of the bases of the systems (almost entirely from recent American works) presented. If and when the principles of phylogenetic classification come to be applied to his groups, we can expect considerable changes in the systems tabulated by Wilson. Following these chapters is one on "Pre-social Insects", with interesting examples drawn from spiders as well as from various insect orders. Curiously, the Embioptera receive only a single mention, and the Zoraptera none at all, in the entire book.

The remainder of the book is a series of chapters devoted to diverse biological topics related to social insects. A chapter on "The Population Dynamics of Colonies" draws fairly heavily on the work of the British M. V. Brian on Myrmica ants, and reproduces some of his mathematical treatment. Symbiosis, considered in two chapters, is taken to include all forms of parasitism, and a useful table of symbiotes of social insects is included. One of his more controversial chapters is one on "The Genetic Theory of Social Behaviour", which would serve very well to stimulate student discussion groups, as would the following one on "Compromises and Optimization in Social Evolution".

Wilson devotes a final chapter to "The Prospects for a Unified Sociobiology", in which he states "The formulation of a theory of sociobiology constitutes, in my opinion, one of the great manageable problems of biology for the next twenty or thirty years". His comparison of vertebrate and insect societies leads to the challenging conclusion: "Had the vertebrates gone the same route [of reproductive specialization], the results would have been much more spectacular. The individual bird or mammal, possessing a brain vastly larger than that of an insect, might have been shaped into a comparably better specialist. The vertebrate society then could have evolved into an unimaginably more complex, efficient unit-at the price, of course, of independent action on the part of its members. Vertebrates have instead remained chained to the cycle of individual reproduction. This forever enhances freedom of the individual at the expense of efficiency on the part of society." He leaves us to draw what conclusions we will.

This handsome book will undoubtedly be widely read and influential; it should serve to recruit more students to the study of social insects, as well as to enhance the scientific status of entomology and of its author.

\section{R. A. Crowson}

\section{African Cichlidae}

The Cichlid Fishes of the Great Lakes of Africa: Their Biology and Evolution. By G. Fryer and T. D. Iles. Pp. $x v+641$. (Oliver and Boyd: Edinburgh, May 1972.) $\quad £ 12$.

MosT authors must have been nagged at one time or another by the thought that some of their data would be "lost", or their impact obscured, through unavoidable publication in an inappropriate place. Those of us who have worked on African cichlid fishes can now relax, at least on that score. Fryer and Iles have done an extremely meticulous job of finely carding nearly half a century's literature. From the resulting strands they have woven a text which is likely to remain a first source of primary references to work on the biology and evolution of these fascinating fishes. New ideas and reappraisals of old controversies add to the book's value.

Rightly, I think, the authors have confined themselves to the cichlids of the major African lakes, especially Lakes Malawi, Victoria and Tanganyika. It is in these lakes that the cichlids have undergone their most spectacular outbursts of speciation and 